Fachbereich 5

Wirtschaftswissenschaften, Wirtschaftsinformatik und Wirtschaftsrecht

Volkswirtschaftliche Diskussionsbeiträge

Discussion Papers in Economics

No. $142-10$

May 2010

Thomas Eichner · Rüdiger Pethig

International carbon emissions trading and strategic incentives to subsidize green energy 


\section{Universität Siegen}

Fachbereich 5

Wirtschaftswissenschaften, Wirtschaftsinformatik und Wirtschaftsrecht

Fachgebiet Volkswirtschaftslehre

Hölderlinstraße 3

D-57068 Siegen

Germany

http://www.uni-siegen.de/fb5/vwl/

ISSN 1869-0211

Available for free from the University of Siegen website at http://www.uni-siegen.de/fb5/vwl/research/diskussionsbeitraege/

Discussion Papers in Economics of the University of Siegen are indexed in RePEc and can be downloaded free of charge from the following website:

http://ideas.repec.org/s/sie/siegen.html 


\title{
International carbon emissions trading and strategic incentives to subsidize green energy ${ }^{*}$
}

\author{
Thomas Eichner \\ Department of Economics, University of Hagen \\ Rüdiger Pethig \\ Department of Economics, University of Siegen
}

\begin{abstract}
This paper examines strategic incentives to subsidize green energy in a group of countries that operates an international carbon emissions trading scheme. Welfare-maximizing national governments have the option to discriminate against energy from fossil fuels by subsidizing green energy, although in our model green energy promotion is not efficiency enhancing. The cases of small and large countries turn out to exhibit significantly differences. While small countries refrain from subsidizing green energy and thus implement the efficient allocation, large permit-importing countries subsidize green energy in order to influence the permit price in their favor.
\end{abstract}

JEL Classifications: H21, Q42, Q48

Keywords: emissions trading, black energy, green energy, energy subsidies

\footnotetext{
* Eichner: Department of Economics, University of Hagen, Universitätsstr. 41, 58097 Hagen, Germany, email: thomas.eichner@fernuni-hagen.de; Pethig: Department of Economics, University of Siegen, Hölderlinstr. 3, 57068 Siegen, Germany, email: pethig@vwl.wiwi.uni-siegen.de.
} 


\section{Introduction}

In 2005 the European Union established an EU-wide $\mathrm{CO}_{2}$ emissions trading system to reduce its greenhose gas emissions by 8 \% in 2012 from its baseline emissions in 1990 . Similarly, in August 2007 the Western Climate Initiative, launched by seven US states and four Canadian provinces, planned to lay the foundation for an international emissions trading scheme that involves both the United States and Canada and pursues the goal of reducing greenhouse gas emissions by $15 \%$ from 2005 levels by 2020 .

Countries under the umbrella of an international emissions trading scheme, e.g. the EU member states, are observed to promote green energy by feed-in tariffs or green tradable certificates. Feed-in tariffs (or renewable energy tariffs) are output subsidies per unit of produced energy (Menanteau et al. 2003) and green certificates are tradable commodities 'earned' by green energy producers for each unit of their output which producers of black energy are then obliged to purchase in some proportion to their output. Feed-in tariffs are in operation in 63 jurisdictions around the world, including Canada, France, Germany, and in a dozen states in the United States. National trading schemes of green certificates are in use in e.g. the UK, Italy and some US states.

International emissions trading schemes aim at coping with climate change by curbing greenhouse gas emissions, but the economic rationale for promoting green energy is less clear. The literature suggests two justifications for combining emissions control with green energy promotion policies. In the presence of learning spillovers ${ }^{1}$ subsidizing the use of renewable energy is efficiency enhancing especially in their innovatory phase in order to spur learning effects that are beneficial for renewable energy producers as well as for society at large (Bläsi and Requate 2007, Fischer and Newall 2008, Lehmann 2009). The second justification is energy security, i.e. the reduction of the dependence from insecure fossil fuel imports. Assuming uncertainty about the import price of fossil fuel, Eichner and Pethig (2009b) show that risk averse governments of small open economies may choose to subsidize green energy to reduce the price uncertainty.

The present paper suggests and investigates another rationale for subsidizing green energy. Countries may have a strategic incentive to use (positive or negative) green subsidies

\footnotetext{
${ }^{1}$ Learning spillovers are related to technological or R\&D spillovers. For an analysis of technological spillovers in the environmental context we refer to Goulder and Mathai (2000).
} 
in order to manipulate in their favour the permit price. To make this thesis precise, we consider a group of countries operating joint emissions trading scheme. Each country produces green energy with a domestic resource and black energy by means of fossil fuel imported from the rest of the world. The domestic resource is also used for the production of an internationally tradable composite consumer good.

Focussing on competitive economies and welfare-maximizing governments, we show that it is efficient for the group of countries to refrain from subsidizing green energy. The governments of small open countries who take as given the price in the international permit market find it optimal not to subsidize green energy and thus also secure efficiency from the viewpoint of the group of countries. In contrast, governments of large countries are aware that their policy affects the permit price and therefore find it optimal to use the subsidy for distorting the permit price in their favor while behaving Nash with regard to the other countries' subsidies. The strategic incentives to promote green energy differ markedly between permit-exporting and permit-importing countries.

In the field of international environmental economics strategic choice of environmental policy instruments has been investigated e.g. by Barrett (1994), Rauscher (1994) and Ulph (1996). There is only a small literature, however, that investigates strategic incentives of national regulation in the context of international emissions trading. In Bréchet and Peralta (2008) and Eichner and Pethig (2009a) national governments levy energy or emissions taxes to manipulate the permit price in their favor. In Santore et al. (2003) national regulators impose emissions taxes and tariffs to affect the permit price in a model with spillovers. We are not aware of contributions to the literature that explore - as we aim to do in the present paper - the interaction of international emissions trading and national green energy promotion policies.

The present paper is organized as follows. Section 2 sets up the model. Section 3 characterizes the efficient allocation and the first-best policy-supported competitive equilibrium for the group of countries. Section 4 analyzes subsidy competition for the smallcountry case of governments which ignore the impact of their policy on the permit price and for the large-country case of governments which account for the impact of their policies on the permit price. Section 6 concludes. 


\section{The model}

Consider a group of $n$ countries embedded in the world economy. All countries in that group participate in an international $\mathrm{CO}_{2}$ emissions trading scheme to be specified below. Country $i=1, \ldots, n$ employs the resource input $r_{x i}$ to produce the amount $x_{s i}$ of a consumer good (good $X)$, the same in all countries, according to the production function

$$
x_{s i}=X^{i}\left(r_{x i}\right)
$$

Moreover, country $i$ produces energy,

$$
z_{s i}=b_{s i}+g_{s i},
$$

consisting of black energy $b_{s i}$ and green energy $g_{s i}$. Both kinds of energy are considered in (2) to be perfect substitutes, for simplicity. Black energy is generated from fossil fuel $e_{i}$,

$$
b_{s i}=B^{i}\left(e_{i}\right)
$$

and green energy is produced with the resource input $r_{g i}$ via

$$
g_{s i}=G^{i}\left(r_{g i}\right)
$$

The production functions $X^{i}, B^{i}$ and $G^{i}$ are strictly increasing and strictly concave in their arguments. The representative consumer of country $i$ derives utility

$$
u_{i}=U^{i}\left(x_{i}, z_{i}\right)
$$

from consuming $x_{i}$ units of good $X$ and the amount $z_{i}$ of energy. The utility function $U^{i}$ is strictly increasing in both arguments and quasi-concave.

$\mathrm{CO}_{2}$ emissions are proportional to the input of fossil fuel and therefore we simply use $e_{i}$ to denote the fuel input as well as $\mathrm{CO}_{2}$ emissions. The group of countries as a whole has committed to restrict its total carbon emissions to some level $\bar{c}>0$. To meet that emissions target $\bar{c}$, the countries take part in a joint emissions trading scheme. Each country $i$ is assigned a national emissions cap $c_{i}$ such that $\sum_{j} c_{j}=\bar{c}$. The national emissions caps $c_{i}$ are taken as given throughout the present paper. The equilibrium on the permit market, 


$$
\sum_{j} e_{j}=\sum_{j} c_{j}
$$

is brought about by the permit price $\pi_{e}$. Good $X$ and fossil fuel are traded on world markets at prices $p_{x}$ and $p_{e}$, respectively, which all countries take as given. Energy and the resource are traded on domestic markets in each country $i$ at prices $p_{z i}$ and $p_{r i}$, respectively. The conditions for clearing those markets are

$$
z_{i}=z_{s i} \text { and } \quad r_{x i}+r_{g i}=\bar{r}_{i} \text {, }
$$

where $\bar{r}_{i}$ is the resource endowment of country $i$ owned by its representative consumer. With this information, country i's balance of payments (current account) is

$$
\pi_{e}\left(c_{i}-e_{i}\right)+p_{x}\left(x_{s i}-x_{i}\right)-p_{e} e_{i}=0 .
$$

\section{$3 \quad$ Allocative (in)efficiency and green subsidies}

In this section we determine the Pareto efficient allocation via maximizing the weighted sum of utilities under the constraints (1) - (4), (6), (7) and $\sum_{j}\left[p_{x}\left(x_{s j}-x_{j}\right)-p_{e} e_{j}\right]=0$. The last equation is the group's consolidated trade balance vis-à-vis the rest of the world. We use that constraint rather than all countries' trade balances (8) to characterize the efficient allocation, because owing to (6) summing (8) over all countries yields

$$
\sum_{j}\left[\pi_{e}\left(c_{j}-e_{j}\right)+p_{x}\left(x_{s j}-x_{j}\right)-p_{e} e_{j}\right]=\sum_{j}\left[p_{x}\left(x_{s j}-x_{j}\right)-p_{e} e_{j}\right]=0 .
$$

The efficient allocation is a solution to the Lagrangean

$$
\begin{aligned}
L= & \sum_{j} \alpha_{j} U^{j}\left(x_{j}, z_{j}\right)+\sum_{j} \lambda_{z j}\left[B^{j}\left(e_{j}\right)+G^{j}\left(r_{g j}\right)-z_{j}\right]+\lambda_{e} \sum_{j}\left(c_{j}-e_{j}\right)+ \\
& +\lambda_{t} \sum_{j}\left[p_{x}\left(X^{j}\left(r_{x j}\right)-x_{j}\right)-p_{e} e_{j}\right]+\sum_{j} \lambda_{r j}\left(r_{j}-r_{g j}-r_{x j}\right),
\end{aligned}
$$

where $c_{j}, p_{e}$ and $p_{x}$ are positive constants, $\lambda_{z j}, \lambda_{e}, \lambda_{t}$ and $\lambda_{r j}$ are Lagrange multipliers and $\alpha_{j}$ denote constant positive welfare weights. Simple calculations show that the allocation of the multi-country economy (1) - (8) is efficient, if and only if

$$
\frac{U_{x}^{i}}{U_{z}^{i}}=\frac{p_{x}}{\mu_{z i}}, \quad \frac{G_{r}^{i}}{X_{r}^{i}}=\frac{p_{x}}{\mu_{z i}}, \quad \text { and } \quad \mu_{z i} B_{e}^{i}=\mu_{e}+p_{e} \quad \text { for } i=1, \ldots, n,
$$


where $\mu_{z i}:=\lambda_{z i} / \lambda_{t}$ and $\mu_{e}:=\lambda_{e} / \lambda_{t}$. The first equation in (9) is the rule for efficient consumption, the second and third equations are rules for efficient production. The equation $\mu_{z i} B_{e}^{i}=\mu_{e}+p_{e}$ reflects the well-known efficiency requirement of equalizing marginal abatement costs across countries.

Next we assess the efficiency properties of competitive markets when the emissions trading scheme is in operation and green energy is subsidized. For that purpose, we introduce a green energy subsidy ${ }^{2}$ (subsidy, for short) in each country $i$ at rate ${ }^{3} s_{i}$, and consider the price taking agents' optimization plans: The producers of good $X$, green energy and black energy maximize profits ${ }^{4}$

$\phi_{x i}=p_{x} X^{i}\left(r_{x i}\right)-p_{r i} r_{x i}, \phi_{g i}=\left(p_{z i}+s_{i}\right) G^{i}\left(r_{g i}\right)-p_{r i} r_{g i}$ $\phi_{b i}=p_{z i} B^{i}\left(e_{i}\right)-\pi_{e}\left(e_{i}-c_{i}\right)-p_{e} e_{i}$, respectively, and the consumer maximizes her utility (5) subject to the budget constraint $p_{x} x_{i}+p_{z i} z_{i} \leq p_{r i} \bar{r}_{i}+\phi_{x i}^{*}+\phi_{g i}^{*}+\phi_{b i}^{*}-s_{i} g_{s i}$, where $\phi_{x i}^{*}$, $\phi_{g i}^{*}$ and $\phi_{b i}^{*}$ are maximum profits and where $s_{i} g_{s i}$ is a lumpsum tax levied on the consumer and used to subsidize green energy production. The pertaining first-order conditions are

$$
\frac{U_{x}^{i}}{U_{z}^{i}}=\frac{p_{x}}{p_{z i}}, \quad \frac{G_{r}^{i}}{X_{r}^{i}}=\frac{p_{x}}{p_{z i}+s_{i}} \quad \text { and } \quad p_{z i} B_{e}^{i}=\pi_{e}+p_{e}
$$

From comparing the equations (9) and (10) immediately follows

Proposition 1. The competitive equilibrium of the n-country economy with emissions trading and subsidy rates $\left(s_{1}, \ldots, s_{n}\right)$ is efficient, if and only if $s_{1}=\ldots=s_{n}=0$.

\footnotetext{
${ }^{2}$ As mentioned above (Section 1), in practice green energy promotion often takes the form of feed-in tariffs or green certificates schemes. However, at the high level of abstraction of our model the incidence of these policy schemes is the same as that of government subsidies.

${ }^{3}$ The rate $s_{i}$ is not sign-constrained. To avoid clumsy wording, we refer to $s_{i}$ not only if $s_{i}>0$, but also if $s_{i}<0$, in which case it is a tax on green energy rather than a subsidy (in the narrow sense).

${ }^{4}$ According to the definition of $\phi_{b i}$ the producer of black energy gets the permit endowment $c_{i}$ for free. The alternative assumption of auctioning permits would leave the results unchanged at the high level of abstraction of our model.
} 
The clear message of Proposition 1 is that for the group of countries as a whole, subsidies are distortionary and render inefficient the equilibrium allocation. That result does not come as a surprise because, given the emissions trading scheme, there are no externalities or other market imperfections in our n-country economy and therefore any subsidy or tax (based on endogenous economic variables) is bound to reduce the welfare of the group of countries. If curbing emissions is considered the only policy target and if group efficiency is an agreed-upon target, Proposition 1 advises governments to abstain from subsidizing green energy altogether. It is not clear, though, whether green energy subsidies are also unfavorable from the viewpoint of individual countries whose governments (also) consider curbing emissions as the only policy target but focus on national welfare rather than on group efficiency. We will address that issue in the next section.

\section{Subsidy competition}

The small country case. Consider first a small open country $i$ whose government has at its disposal a green energy subsidy, takes the permit price $\pi_{e}$ as given and aims at maximizing its country's welfare defined as its representative consumer's utility. The comparative static effects of a change in $s_{i}$ and $\pi_{e}$ (derived in the Appendix A) on country i's welfare are

$$
\frac{\mathrm{d} u_{i}}{\lambda_{i}}=-s_{i} \alpha_{i} \mathrm{~d} s_{i}+\left(c_{i}-e_{i}-s_{i} \beta_{i}\right) \mathrm{d} \pi_{e},
$$

where $^{5} \quad \alpha_{i}:=\left[\left(\frac{p_{z i}}{x_{i}}+\frac{1}{z_{i}}\right) B_{e}^{i 2}-\sigma_{i} B_{e e}^{i}\right] \frac{G_{r}^{i 2}}{D_{i}}>0, \beta_{i}:=\left[\left(\frac{p_{z i}}{x_{i}}+\frac{1}{z_{i}}\right) B_{e}^{i}-\frac{\left(c_{i}-e_{i}\right) p_{z i} B_{e e}^{i}}{x_{i}}\right] \frac{G_{r}^{i 2}}{D_{i}}$, $D_{i}:=\left[\left(\frac{p_{z i}}{x_{i}}+\frac{1}{z_{i}}\right) B_{e}^{i 2}-\sigma_{i} B_{e e}^{i}\right] \gamma_{i}-\left(\frac{X_{r}^{i}}{x_{i}}+\frac{G_{r}^{i}}{z_{i}}\right) p_{z i} B_{e e}^{i} G_{r}^{i}>0, \quad \gamma_{i}:=-X_{r r}^{i}-\left(p_{z i}+s_{i}\right) G_{r r}^{i}>0$.

The government of country $i$ takes the permit price as given (which means that we set $\mathrm{d} \pi_{e}$ $=0$ in (11)) and chooses its subsidy such that $\mathrm{d} u_{i}=0$. The straightforward conclusion from (11) is

\footnotetext{
${ }^{5}$ We introduce these terms (and some more below) to improve the readability of the paper. The list of all auxiliatory terms defined is provided in the Appendix B.
} 
Proposition 2. (Small country case). If the government of country i seeks to maximize national welfare taking the permit price as given, it refrains from subsidizing green energy.

According to Proposition 2, the competitive equilibrium without subsidies is therefore not only efficient from the viewpoint of the group of countries (Proposition 1) but also welfare maximizing from the viewpoint of individual governments of small countries (Proposition 2) capable to subsidize green energy.

The large country case. Now we turn to green energy subsidies in a group of large open countries whose welfare maximizing governments account for the influence of their policy on the permit price $\pi_{e}$. Analogous to our procedure in the small country case, we envisage an individual country $i$ and explore that country's change in welfare when subsidy rates vary. In contrast to (11), however, the government now takes into account in its optimization calculus how the equilibrium permit price changes in response to variations in its own subsidy and in the other countries' subsidies. Formally, (11) is replaced by

$$
\frac{\mathrm{d} u_{i}}{\lambda_{i}}=-s_{i} \alpha_{i} \mathrm{~d} s_{i}+\left(c_{i}-e_{i}-s_{i} \beta_{i}\right) \sum_{j} \frac{\mathrm{d} \pi_{e}}{\mathrm{~d} s_{j}} .
$$

To determine the differential quotients $\mathrm{d} \pi_{e} / \mathrm{d} s_{j}$ we need to re-consider the fossil fuel consumption, $e_{i}=E^{i}\left(\pi_{e}, s_{i}\right)$, of a country $i$ that takes as given both the subsidy $s_{i}$ and the permit price $\pi_{e}{ }^{6}$, and we then need to specify how $e_{i}$ varies in response to small exogenous changes in $s_{i}$ and $\pi_{e}$. In the Appendix A we show that

$$
\begin{aligned}
& E_{s_{i}}^{i}=\frac{\partial e_{i}}{\partial s_{i}}=-\underbrace{\left(\frac{X_{r}^{i}}{x_{i}}+\frac{G_{r}^{i}}{Z_{i}}\right) \frac{G_{r}^{i}}{D_{i}}}_{=: \delta_{i}>0} \cdot B_{e}^{i}=-\delta_{i} B_{e}^{i}<0 \text { and } \\
& E_{\pi_{e}}^{i}=-\underbrace{\left(\frac{X_{r}^{i}}{x_{i}}+\frac{G_{r}^{i}}{Z_{i}}\right) \frac{G_{r}^{i}}{D_{i}}}_{=: \delta_{i}}-\underbrace{\frac{\left[x_{i} \sigma_{i}-\left(c_{i}-e_{i}\right) p_{z i} B_{e}^{i}\right] \gamma_{i}}{p_{z i} x_{i} D_{i}}}_{=: \zeta_{i}}=-\left(\delta_{i}+\zeta_{i}\right) .
\end{aligned}
$$

\footnotetext{
${ }^{6} E^{i}\left(\pi_{e}, s_{i}\right)$ is the equilibrium quantity of fossil fuel consumption, if and only if $\pi_{e}$ is the equilibrium permit price.
} 
From (14) it is straightforward that $\zeta_{i} \geq 0$ and hence $E_{\pi_{e}}^{i}<0$, if $c_{i} \leq e_{i}$. However, for permit-exporting countries the sign of $\zeta_{i}$ is unclear. Later we will examine in some detail the determinants of the sign of $E_{\pi_{e}}^{i}$ for permit-exporting countries because that sign will play an important role for the conclusions to be derived.

Next we rewrite equation (6) as $\sum_{j} E^{j}\left(\pi_{e}, s_{j}\right)=\sum_{j} c_{j}$ and observe that after some (small) exogenous variations in subsidies a new equilibrium is attained, if and only if $\mathrm{d} e=\sum_{j} E_{\pi_{e}}^{j} \mathrm{~d} \pi_{e}+\sum_{j} E_{s_{j}}^{j} \mathrm{~d} s_{j}=0$ or

$$
\mathrm{d} \pi_{e}=-\frac{\sum_{j} E_{s_{j}}^{j} \mathrm{~d} s_{j}}{\sum_{j} E_{\pi_{e}}^{j}}=-\frac{\sum_{j} \delta_{j} B_{e}^{j} \mathrm{~d} s_{j}}{\sum_{j}\left(\delta_{j}+\zeta_{j}\right)}
$$

where $\delta_{i}$ and $\zeta_{i}$ are defined in (13) and (14). We insert (15) into (12) and obtain

$$
\frac{\mathrm{d} u_{i}}{\lambda_{i}}=-\left[s_{i} \alpha_{i}+\frac{\left(c_{i}-e_{i}-s_{i} \beta_{i}\right) \delta_{i} B_{e}^{i}}{\sum_{j}\left(\delta_{j}+\zeta_{j}\right)}\right] \mathrm{d} s_{i}-\frac{\left(c_{i}-e_{i}-s_{i} \beta_{i}\right) \sum_{j \neq i} \delta_{j} B_{e}^{j} \mathrm{~d} s_{j}}{\sum_{j}\left(\delta_{j}+\zeta_{j}\right)}
$$

To characterize government $i$ 's best reply to given subsidy rates of all other countries we set $\mathrm{d} s_{j}=0$ for all $j \neq i$. That converts (16) into

$$
\frac{\mathrm{d} u_{i}}{\mathrm{~d} s_{i} \lambda_{i}}=-\frac{s_{i} \eta_{i}+\left(c_{i}-e_{i}\right) \delta_{i} B_{e}^{i}}{\sum_{j}\left(\delta_{j}+\zeta_{j}\right)}
$$

where $\eta_{i}:=\alpha_{i} \sum_{j}\left(\delta_{j}+\zeta_{j}\right)-\beta_{i} \delta_{i} B_{e}^{i}=\alpha_{i}\left(\sum_{j \neq i} \delta_{j}+\sum_{j} \zeta_{j}\right)-\frac{\delta_{i} p_{z i} B_{e e}^{i} G_{r}^{i 2}}{\gamma_{i}} \zeta_{i}$ or

$$
\eta_{i}=\alpha_{i} \sum_{j \neq i}\left(\delta_{j}+\zeta_{j}\right)+\theta_{i} \zeta_{i} \text { with } \theta_{i}:=\frac{\alpha_{i} \gamma_{i}-\delta_{i} p_{z i} B_{e e}^{i} G_{r}^{i 2}}{\gamma_{i}}>0
$$

The first-order condition for the best reply is $\frac{\mathrm{d} u_{i}}{\lambda_{i} \mathrm{~d} s_{i}}=0$ which implies in view of (17)

$$
s_{i}=-\frac{\left(c_{i}-e_{i}\right) \delta_{i} B_{e}^{i}}{\eta_{i}}
$$


The conclusion to be drawn from (19) crucially depends on the sign of $\eta_{i}$. As $\alpha_{i}, \delta_{i}$ and $\theta_{i}$ are positive for all $i$, while $\zeta_{i}$ may but need not be negative for permit-exporting countries, the sign of $\eta_{i}$ is unclear. $\zeta_{i}>0$ for all $i$ is an obvious sufficient condition for $\eta_{i}>0$ (and for $E_{\pi_{e}}^{i}<0$ as well). However, we wish to make use of weaker conditions for $\eta_{i}>0$. First we impose the constraint $E_{\pi_{e}}^{i}=-\left(\delta_{i}+\zeta_{i}\right)<0$ for all $i$ rather than $\zeta_{i}>0$ for all $i$ and we will demonstrate later that $E_{\pi_{e}}^{i}<0$ does not appear to be an unreasonably strong restriction. Closer inspection of (14) shows that $E_{\pi_{e}}^{i}<0$ for all $i$ is equivalent to

$$
\frac{c_{i}-e_{i}}{e_{i}}<\left(\frac{X_{r}^{i}}{x_{i}}+\frac{G_{r}^{i}}{z_{i}}\right) \frac{x_{i} G_{r}^{i}}{\gamma_{i} e_{i} B_{e}^{i}}+\frac{\sigma_{i} x_{i}}{p_{z i} e_{i} B_{e}^{i}} \quad \text { for } i=1, \ldots, n .
$$

The right side of that inequality is positive so that (20) is satisfied for all permitexporting countries for which $\left(c_{i}-e_{i}\right) / e_{i}$ is not too large. $\left(c_{i}-e_{i}\right) / e_{i}$ is the permit export as a share of domestic permit use. Unfortunately, (20) still leaves the sign of $\eta_{i}$ ambiguous. We therefore need to introduce " $\eta_{i}>0$ for $i=1, \ldots, n$ " as a second constraint which can be shown to be equivalent to the inequality

$$
\frac{c_{i}-e_{i}}{e_{i}}<\frac{\sigma_{i} x_{i}}{p_{z i} e_{i} B_{e}^{i}}+\frac{\alpha_{i} x_{i} D_{i} \sum_{j \neq i}\left(\delta_{j}+\zeta_{j}\right)}{\gamma_{i} e_{i} B_{e}^{i} \theta_{i}} \text { for } i=1, \ldots, n \text {. }
$$

When combined with (20) which is equivalent to $\delta_{i}+\zeta_{i}>0$, the right side of (21) is positive and greater than $\sigma_{i} x_{i} / p_{z i} e_{i} B_{e}^{i}$. From this observation combined with (19) follows immediately

Proposition 3. (Large country case). Suppose the governments of all countries seek to maximize national welfare and account for the impact of their green energy subsidy on the permit price. If the Nash equilibrium in subsidy rates of the n-country economy satisfies (20) and (21), the equilibrium subsidy of country i is characterized by

$$
\text { sign } s_{i}=-\operatorname{sign}\left(c_{i}-e_{i}\right) \text {. }
$$


According to (22) the government of country $i$ chooses $s_{i}>0\left[s_{i}<0\right]$ if and only if country $i$ imports [exports] permits. The permit-importing country has an incentive to subsidize green energy $\left(s_{i}>0\right)$ to discourage its black energy production as well as its fossil fuel consumption and generation of emissions. The drop in the demand for permits lowers both the permit price and the need for permits and thus the county's permit import bill. That is welfare enhancing up to some point where the distortion in production compensates the advantage of raising the subsidy. Conversely, the permit-exporting country applies a negative subsidy ( $=$ tax) on green energy $\left(s_{i}<0\right)$ to stimulate black energy production and with it the country's permit demand. The intention is to raise the permit price which then increases national income via rising revenues form permit exports. The net advantage of successive increases in the tax rate diminishes because of rising distortions in production. Note that production inefficiencies result whenever $s_{i} \neq 0$, and that the distortions are particularly severe because $s$ is negative for some countries and positive for others.

Negative green energy subsidies (= taxes) do not appear to be a relevant issue in practical policy although they may be found as (possibly unintended) side effects of complex regulation. Assuming that negative subsidies are not viable, e.g. because of strong resistance from green lobby groups, the governments of permit-exporting countries can be conceived to maximize welfare under the additional constraint $s_{i} \geq 0$. Their optimal choice would then be $s_{i}=0$. In other words, if taxing green energy is not feasible permit- exporting countries have strong strategic incentives not to promote green energy.

\section{How restrictive are the preconditions of Proposition 3?}

It is not easy to see how general the result of Proposition 3 is, i.e. how severe the restrictions (20) and (21) are for the result (22). To assess that issue it is convenient to focus on condition (20) - rather than on (21) or on both conditions - and examine the order of magnitude of the right side of the inequality (20) which reads

$$
\left(\frac{X_{r}^{i}}{x_{i}}+\frac{G_{r}^{i}}{z_{i}}\right) \frac{x_{i} G_{r}^{i}}{\gamma_{i} e_{i} B_{e}^{i}}+\frac{\sigma_{i} x_{i}}{p_{z i} e_{i} B_{e}^{i}} .
$$

We aim at offering some thumb estimates of all components of (23). The transformations: 


$$
\begin{aligned}
& \frac{X_{r}^{i}}{x_{i}}+\frac{G_{r}^{i}}{z_{i}}=\frac{1}{x_{i}}\left(X_{r}^{i}+\frac{x_{i}}{z_{i}} G_{r}^{i}\right)=\frac{p_{r i}}{x_{i}}\left(1+\frac{x_{i}}{\left(p_{z i}+s_{i}\right) z_{i}}\right)=\frac{p_{r i}}{x_{i}} \cdot \frac{\left(p_{z i}+s_{i}\right) z_{i}+x_{i}}{\left(p_{z i}+s_{i}\right) z_{i}} . \\
& \gamma_{i}:=-X_{r r}^{i}-\left(p_{z i}+s_{i}\right) G_{r r}^{i}=\frac{p_{r i}}{r_{g i}}\left(\frac{r_{g i}}{r_{x i}} \varepsilon_{r r}^{x i}+\varepsilon_{r r}^{g i}\right) \text {, with } \varepsilon_{r r}^{x i}:=-\frac{r_{x i} X_{r r}^{i}}{X_{r}^{i}} \text { and } \varepsilon_{r r}^{g i}:=-\frac{r_{g i} G_{r r}^{i}}{G_{r}^{i}} \text {. } \\
& \frac{G_{r}^{i}}{e_{i} B_{e}^{i}}=\frac{g_{i}}{b_{i} r_{g i}} \cdot \frac{\varepsilon_{r}^{g i}}{\varepsilon_{e}^{b i}} \text {, with } \varepsilon_{r}^{g i}:=\frac{r_{g i} G_{r}^{i}}{g_{i}} \text { and } \varepsilon_{e}^{b i}:=\frac{e_{i} B_{e}^{i}}{b_{i}} \text {. }
\end{aligned}
$$

turn (23) into

$$
\underbrace{\left[\frac{\left(p_{z i}+s_{i}\right) z_{i}+x_{i}}{\left(p_{z i}+s_{i}\right) z_{i}}\right.}_{[1]} \cdot \underbrace{\frac{1}{\left(r_{g i} / r_{x i}\right) \varepsilon_{r r}^{x i}+\varepsilon_{r r}^{g i}}}_{[2]} \cdot \underbrace{\frac{\varepsilon_{r}^{g i}}{\varepsilon_{e}^{b i}}}_{[3]} \cdot \underbrace{\frac{1}{p_{r i}}}_{[4]} \cdot \underbrace{\left.\frac{g_{i}}{b_{i}}\right]}_{[5]}+\underbrace{\left[\frac{1}{\varepsilon_{e}^{b i}}\right.}_{[6]} \cdot \underbrace{\frac{p_{x} x_{i}}{p_{z i} b_{i}}}_{[7]} \cdot \underbrace{\left.\sigma_{i}\right]}_{[8]}
$$

What do we know about the order of magnitude of the terms [1] through [8] in (24)? The term [1] is much larger than one, because the value of energy, $\left(p_{z i}+s_{i}\right) z_{i}$, is far less than the value $x_{i}=p_{x} x_{i}$ of the composite consumer good $X$. In term [2] the ratio $\left(r_{g i} / r_{x i}\right)$ is significantly smaller than one, and the elasticities $\varepsilon_{r r}^{g i}$ and $\varepsilon_{r r}^{x i}$ are in the interval ]0,1[ for iso-elastic production functions. Hence [2] can be expected to be greater than or close to one, and [3] $\approx 1$ is also plausible. To determine a lower bound for [4] we make use of $x_{s i}>p_{r i} r_{x i}$ (positive profit) and find that $\frac{1}{p_{r i}}>\frac{r_{x i}}{x_{s i}}$. For an iso-elastic production function $x_{s i}=r_{x i}^{\xi}$ with $\left.\xi \in\right] 0,1\left[\right.$ we have $\frac{r_{x i}}{r_{x i}^{\xi}}=r_{x i}^{1-\xi}$. Since $r_{x i}$ tends to grow with increasing resource endowment, $\overline{r_{i}}$, [4] will be larger than one for sufficiently large $\overline{r_{i}}$. Summing up, the product [1] [2] [3] [4] can be safely assumed to be much larger than one. However, the term [5] is far smaller than one which makes it very difficult to place a reliable number on the entire product [1]·[2]·[3]·[4]·[5]. Nonetheless our above arguments lead us to consider $[1] \cdot[2] \cdot[3] \cdot[4] \cdot[5] \approx 1$ a reasonable and rather low estimate.

Consider next the product [6]·[7].[8]. Since $\left.\varepsilon_{e}^{b i} \in\right] 0,1[$, the term [6] in (24) is clearly greater than one. The term [7] is significantly larger than one because good $X$ represents all consumer goods in our model whereas the value of black energy is a fairly small share of 
GDP only 5-8\% (EAI 2008). ${ }^{7}$ Consequently, even if we allow for small values of $\sigma_{i}$, say values well below one, the product [6]·[7]·[8] is still likely to be larger than one. Hence we consider $[1] \cdot[2] \cdot[3] \cdot[4] \cdot[5]+[6] \cdot[7] \cdot[8] \approx 2$ a very coarse but fairly conservative estimate for the entire term in (24). If we consider $\left(\frac{X_{r}^{i}}{x_{i}}+\frac{G_{r}^{i}}{z_{i}}\right) \frac{x_{i} G_{r}^{i}}{\gamma_{i} e_{i} B_{e}^{i}}+\frac{\sigma_{i} x_{i}}{p_{z i} e_{i} B_{e}^{i}}=2$ in (20), we find that Proposition 3 covers Nash equilibria in which permit-exporting countries do not export more than two thirds (67\%) of their permit endowment, $c_{i}$. In the emissions trading scheme of the European Union no country comes even close to an export share of permits exceeding 60\%. (Trotignon and Delbosc 2008). In light of these plausibility arguments (guided by stylized empirical estimates) the condition (20) does not appear to be unreasonably restrictive at all.

So far we have restricted our attention on the constraint (20). Obviously, if (21) rather than (20) is binding for some permit-exporting countries, Proposition 3 is somewhat less general than suggested by our discussion of (24) above. Nonetheless, even in that case the inequalities (20) and (21) are still less restrictive than the alternative constraint that is sufficient for reaching the conclusion (22), namely the condition $\zeta_{i}>0$ for $i=1, \ldots, n$ or

$$
\frac{c_{i}-e_{i}}{e_{i}}<\frac{\sigma_{i} x_{i}}{p_{z i} e_{i} B_{e}^{i}} \text { for } i=1, \ldots, n
$$

The preceding discussion showed that $E_{\pi_{e}}^{i}=-\left(\delta_{i}+\zeta_{i}\right)<0$ is not unrealistic for permitexporting countries. To reinforce that assessment we wish to identify the economic drivers of the sign of $E_{\pi_{e}}^{i}$ by reference to the comparative statics of the small open economy carried out in the Appendix A. According to that analysis, in permit-exporting and -importing countries alike ${ }^{8} \Delta \pi_{e}>0$ stimulates green energy production, reduces the production of good $X$, and raises the consumer price of energy, $p_{z i}$, while the consumer good price $p_{x}$ remains constant by assumption. Total energy consumption - and with it necessarily black energy production - shrinks unambiguously only, when the country imports permits. Under the plausible assumption that the income elasticities of energy and good $X$ are positive,

\footnotetext{
${ }^{7}$ EIA (2008) reports that over 2000-2008 in the US the total energy expenditures per GDP lie between 6 and $9 \%$. Since the share of black energy is $90 \%$, the black energy share of GDP amounts to 5 to $8 \%$.

${ }^{8} \Delta$ indicates a finite change of a variable.
} 
$\Delta z_{i}>0$ follows from $\Delta \pi_{e}>0$ in permit-exporting countries, if and only if the following conditions are satisfied:

(a) National income must rise to generate a positive income effect $\Delta z_{i}^{I}>0$;

(b) The negative substitution effect $\Delta z_{i}^{S}<0$ due to $\Delta\left(p_{z i} / p_{x}\right)>0$ must not overcompensate ${ }^{9}$ the positive income effect: $\Delta z_{i}=\Delta z_{i}^{I}+\Delta z_{i}^{S}>0$.

Even if these conditions hold ${ }^{10}$, black energy and emissions need not necessarily increase, however, because $\Delta z_{i}=\Delta b_{i}+\Delta g_{i}>0$ may be brought about by $\Delta g_{i}>0$ and $\Delta b_{i}<0$.

Therefore, $E_{\pi_{e}}^{i}<0$ appears to be likely for all permit-exporting countries.

\section{Concluding remarks}

The present paper suggests that strategic incentives may be a rationale for subsidizing green energy when countries operate a joint emissions trading scheme. Welfare maximizing governments of large countries put a positive or negative subsidy on green energy in order to manipulate the permit price. Subsidy competition of small countries turns out to be efficient from the perspective of the group of countries, since all countries refrain from green energy subsidies. In contrast, subsidy competition of large countries renders the multi-country economy inefficient. In that case the policy implication is 'subsidy harmonization at the level zero'.

Finally, it must be kept in mind that the simple assumptions of our stylized model put some limits on the generality of results. E.g., energy production takes place under perfect competition which is in stark contrast to energy markets in the real world. The analysis of monopolistic or oligopolistic energy producers is therefore an important task for future research. Also, we assume that energy is traded on domestic markets only and no fossil fuel is supplied in any country of the group. These assumptions may be considered acceptable as a first approximation, e.g. for the European Union, but it is necessary to examine

\footnotetext{
${ }^{9}$ For any given price change $\Delta\left(p_{z i} / p_{x}\right)>0$, the substitution effect $\Delta z_{i}^{S}<0$ is the smaller in absolute terms the smaller is the elasticity of substitution in demand, $\sigma_{i}$.

${ }^{10}$ It is interesting to observe that if the income elasticities of energy and good $X$ are positive and the conditions (a) and (b) hold, then the consumption of good $X$ increases along with energy consumption and therefore the welfare of the country rises.
} 
the robustness of our results with respect to deviations from these assumptions in order to improve our understanding of strategic incentives for or against promoting green energy.

\section{Appendix}

\section{A: Comparative statics of the small open economy}

For convenience of notation, we suppress the index $i$, when there is no risk of confusion, and we set equal to one the price of good $X\left(p_{x} \equiv 1\right)$. For given $c, \bar{r}, p_{e}, p_{x} \equiv 1$ and $\pi_{e}$ an equilibrium of the small open economy ${ }^{11}$ is constituted by prices $p_{r}, p_{z}$ and an allocation $\left(b_{s}, e, g_{s}, r_{g}, r_{x}, s, x_{s}, z, z_{s}\right)$ such that $\left(b_{s}, e, g_{s}, r_{g}, r_{x}, x, x_{s}, z, z_{s}\right)$ is a solution to the agents' optimization problems and the constraints (6) and (7) hold. The 12 variables $b_{s}, e, g_{s}, r_{g}, r_{x}, x, x_{s}, z, z_{s}, \lambda, p_{r}$, and $p_{z}$ are determined by the 12 equations

$$
\begin{aligned}
& b_{s}=B(e), \quad z_{s}=b_{s}+g_{s}, \quad X_{r}\left(r_{x}\right)=p_{r}, \quad \pi_{e}(c-e)+\left(x_{s}-x\right)-p_{e} e=0, \\
& g_{s}=G\left(r_{g}\right), \quad z=z_{s}, \quad\left(p_{z}+s\right) G_{r}\left(r_{g}\right)=p_{r}, \quad U_{x}(x, z)=\lambda, \\
& X_{s}=X\left(r_{x}\right), \quad \bar{r}=r_{x}+r_{g}, \quad p_{z} B_{e}(e)=\pi_{e}+p_{e}, \quad U_{z}(x, z)=\lambda p_{z} .
\end{aligned}
$$

To obtain information on how that equilibrium depends on the subsidy $s$ and on the permit price $\pi_{e}$, we will consider the impact of small changes in those parameters on the equilibrium. For that purpose we eliminate the variables $b_{s}, g_{s}, r_{x}, x_{s}, z, z_{s}, p_{r}$ and $\lambda$ in the 12 equations listed above through substitution thus condensing the 12 equations into the four equations

$$
\begin{aligned}
& \pi_{e}(c-e)+p_{x}\left[X\left(\bar{r}-r_{g}\right)-x\right]-p_{e} e=0, \\
& X_{r}\left(\bar{r}-r_{g}\right)=\left(p_{z}+s\right) G_{r}\left(r_{g}\right), \\
& p_{z} B_{e}(e)=\pi_{e}+p_{e}
\end{aligned}
$$

\footnotetext{
${ }^{11}$ Note that the equilibrium of the small open economy is not an equilibrium of the $n$-country economy. The latter would require the additional constraint (6) to hold and the permit price $\pi_{e}$ to be endogenously determined.
} 


$$
\frac{U_{x}\left[x, B(e)+G\left(r_{g}\right)\right]}{U_{z}\left[x, B(e)+G\left(r_{g}\right)\right]}=\frac{1}{p_{z}}
$$

that determine the endogenous variables $e, r_{g}, x$ and $p_{z}$. Total differentiation of these equations yields

$$
\begin{aligned}
& p_{z} B_{e} \mathrm{~d} e+X_{r} \mathrm{~d} r_{g}+\mathrm{d} x=(c-e) \mathrm{d} \pi_{e}, \\
& \gamma \mathrm{d} r_{g}-G_{r} \mathrm{~d} p_{z}=G_{r} \mathrm{~d} s, \\
& p_{z} B_{e e} \mathrm{~d} e+B_{e} \mathrm{~d} p_{z}=\mathrm{d} \pi_{e}, \\
& \frac{B_{e}}{Z} \mathrm{~d} e+\frac{G_{r}}{\mathrm{Z}} \mathrm{d} r_{g}-\frac{\mathrm{d} x}{x}+\frac{\sigma}{p_{z}} \mathrm{~d} p_{z}=0, \\
& \text { where } \sigma:=\frac{\mathrm{d}\left(\frac{x}{z}\right)}{\frac{x}{z}} \cdot \frac{\frac{U_{z}}{U_{x}}}{d\left(\frac{U_{z}}{U_{x}}\right)} \text { is the substitution elasticity and } \gamma:=-p_{x} X_{r r}-\left(p_{z}+s\right) G_{r r}>0 \text {. }
\end{aligned}
$$

After inserting $\mathrm{d} x$ from (A8) in (A5), the equations (A5), (A6) and (A7) read in matrix notation

$$
\left(\begin{array}{ccc}
\frac{\sigma}{p_{z}} & \left(\frac{p_{z}}{x}+\frac{1}{z}\right) B_{e} & \frac{X_{r}}{x}+\frac{G_{r}}{z} \\
-G_{r} & 0 & \gamma \\
B_{e} & p_{z} B_{e e} & 0
\end{array}\right)\left(\begin{array}{l}
\mathrm{d} p_{z} \\
\mathrm{~d} e \\
\mathrm{~d} r_{g}
\end{array}\right)=\left(\begin{array}{c}
\frac{(c-e)}{x} \mathrm{~d} \pi_{e} \\
G_{r} \mathrm{~d} s \\
\mathrm{~d} \pi_{e}
\end{array}\right) .
$$

We solve the equation system (A9) by using Cramer's rule and obtain after some rearrangements of terms

$$
\begin{aligned}
& \mathrm{d} p_{z}=\left[\gamma B_{e}\left(\frac{p_{z}}{x}+\frac{1}{z}\right)-\frac{\gamma p_{z} B_{e e}}{x}(c-e)\right] \frac{\mathrm{d} \pi_{e}}{D}+p_{z} G_{r} B_{e e}\left(\frac{X_{r}}{x}+\frac{G_{r}}{z}\right) \frac{\mathrm{d} s}{D}, \\
& \mathrm{~d} e=\left[\frac{\gamma B_{e}}{x}(c-e)-\frac{\gamma \sigma}{p_{z}}-\left(\frac{X_{r}}{x}+\frac{G_{r}}{z}\right) G_{r}\right] \frac{\mathrm{d} \pi_{e}}{D}-\left(\frac{X_{r}}{x}+\frac{G_{r}}{z}\right) B_{e} G_{r} \frac{\mathrm{d} s}{D},
\end{aligned}
$$




$$
d r_{g}=\left[\left(\frac{p_{z}}{x}+\frac{1}{z}\right) B_{e} G_{r}-\frac{p_{z}}{x} G_{r} B_{e e}(c-e)\right] \frac{\mathrm{d} \pi_{e}}{D}+\left[\left(\frac{p_{z}}{x}+\frac{1}{z}\right) B_{e}^{2} G_{r}-\sigma G_{r} B_{e e}\right] \frac{\mathrm{d} s}{D},
$$

where $D:=\left(\frac{p_{z}}{x}+\frac{1}{z}\right) \gamma B_{e}^{2}-\sigma \gamma B_{e e}-\left(\frac{X_{r}}{x}+\frac{G_{r}}{Z}\right) p_{z} G_{r} B_{e e}>0$.

Next, we insert (A11) and (A12) in $\mathrm{d} z_{s}=\mathrm{d} z=B_{e} \mathrm{~d} e+G_{r} \mathrm{~d} r_{g}$ to obtain after rearrangements of terms

$$
\mathrm{d} z_{s}=\mathrm{d} z=\left[\gamma B_{e}^{2}(c-e)-(c-e) p_{z} G_{r}^{2} B_{e e}-\frac{1}{p_{z}} \gamma \sigma B_{e}-\frac{s B_{e} G_{r}^{2}}{x}\right] \frac{\mathrm{d} \pi_{e}}{D}-\frac{s B_{e}^{2} G_{r}^{2}}{x} \frac{\mathrm{d} s}{D} .
$$

Making use of (A10) and (A13) in $\frac{\mathrm{d} x}{x}=\frac{\mathrm{d} z}{z}+\sigma \frac{d p_{z}}{p_{z}}$ we obtain

$$
\begin{aligned}
\frac{\mathrm{d} x}{x}= & {\left[\frac{(c-e) \gamma B_{e}^{2}}{z}-p_{z} G_{r}^{2} B_{e e} \frac{(c-e)}{z}-\frac{s B_{e} G_{r}^{2}}{x z}+\frac{\sigma a B_{e}}{x}-\frac{\sigma a B_{e e}}{x}(c-e)\right] \frac{\mathrm{d} \pi_{e}}{D} } \\
& +\left[\sigma G_{r} B_{e e}\left(\frac{X_{r}}{x}+\frac{G_{r}}{z}\right)-\frac{s B_{e}^{2} G_{r}^{2}}{x z}\right] \frac{\mathrm{d} s}{D} .
\end{aligned}
$$

The comparative static results of the small open economy are summarized in Table 1:

\begin{tabular}{|l||c|c|c|c|c|c|c|}
\hline & $\mathrm{d} p_{z}$ & $\mathrm{~d} e, \mathrm{~d} b_{s}$ & $\mathrm{~d} r_{g}, \mathrm{~d} g_{s}$ & $\mathrm{~d} r_{x}$ & $\mathrm{~d} x_{s}$ & $\mathrm{~d} z, \mathrm{~d} z_{s}$ & $\mathrm{~d} x$ \\
\hline \hline $\mathrm{d} s>0$ & - & - & + & - & - & - & - \\
\hline $\mathrm{d} \pi_{e}>0, c>e$ & + & $?$ & + & - & - & $?$ & $?$ \\
\hline $\mathrm{d} \pi_{e}>0, c<e$ & + & - & + & - & - & - & $?$ \\
\hline
\end{tabular}

Table 1: The comparative statics of the small open economy (Assumption: $B_{e}^{i}+e_{i} B_{e e}^{i}>0{ }^{12}$ )

Finally, we insert $\mathrm{d} x$ from (A5) and $p_{z} \mathrm{~d} z=p_{z} B_{e} \mathrm{~d} e+p_{z} G_{r} \mathrm{~d} r_{g}$ into $\mathrm{d} u=U_{x} \mathrm{~d} x+U_{z} \mathrm{~d} z$ and use $U_{x}=U_{z} / p_{z}=\lambda$ and (A2) to obtain

\footnotetext{
${ }^{12}$ If the production function takes the form $B^{i}\left(e_{i}\right)=e_{i}^{m_{i}}$ with $\left.m_{i} \in\right] 0,1\left[\right.$, then $\left(B_{e}^{i}+e_{i} B_{e e}^{i}\right)=m_{i}>0$. The functional form $b_{i}=e_{i}^{\theta_{i}}$ appears to be a mild restriction only on (3).
} 


$$
\frac{\mathrm{d} u}{\lambda}=-s G_{r} \mathrm{~d} r_{g}+(c-e) \mathrm{d} \pi_{e}
$$

With $\mathrm{d} r_{g}$ from (A12) we turn (A15) into (11).

\section{B: Terms defined to ease the exposition}

$$
\begin{aligned}
& \alpha_{i}:=\left[\left(\frac{p_{z i}}{x_{i}}+\frac{1}{z_{i}}\right) B_{e}^{i 2}-\sigma_{i} B_{e e}^{i}\right] \frac{G_{r}^{i 2}}{D_{i}}>0 \quad \beta_{i}:=\left[\left(\frac{p_{z i}}{x_{i}}+\frac{1}{z_{i}}\right) B_{e}^{i}-\frac{\left(c_{i}-e_{i}\right) p_{z i} B_{e e}^{i}}{x_{i}}\right] \frac{G_{r}^{i 2}}{D_{i}} \\
& \gamma_{i}:=-X_{r r}^{i}-\left(p_{z i}+s_{i}\right) G_{r r}^{i}>0 \quad \delta_{i}:=\left(\frac{X_{r}^{i}}{x_{i}}+\frac{G_{r}^{i}}{z_{i}}\right) \frac{G_{r}^{i}}{D_{i}} \\
& \left.\zeta_{i}:=\frac{\left[x_{i} \sigma_{i}-\left(c_{i}-e_{i}\right) p_{z i} B_{e}^{i}\right] \gamma_{i}}{p_{z i} x_{i} D_{i}} \quad \delta_{j}+\zeta_{j}\right)+\theta_{i} \zeta_{i} \\
& \theta_{i}:=\frac{\alpha_{i} \gamma_{i}-\delta_{i} p_{z i} B_{e e}^{i} G_{r}^{i 2}}{\gamma_{i}}>0 \\
& D_{i}:=\left[\left(\frac{p_{z i}}{x_{i}}+\frac{1}{z_{i}}\right) B_{e}^{i 2}-\sigma_{i} B_{e e}^{i}\right] \gamma_{i}-\left(\frac{X_{r}^{i}}{x_{i}}+\frac{G_{r}^{i}}{z_{i}}\right) p_{z i} B_{e e}^{i} G_{r}^{i}>0
\end{aligned}
$$

\section{References}

Barrett, S (1994): Strategic environmental policy and international trade. Journal of Public Economics 54, 325 - 338.

Bläsi, A. and T. Requate (2007): Subsidies for wind power: surfing down the learning curve? CAU Economic Working Paper 2007 - 28, Kiel.

Bréchet, T. and S. Peralta (2008): The race for polluting permits. CEPR discussion paper No. 6209, London.

EIA (2008): Energy consumption, expenditures and emissions indicators, Table 1.5, US.

Eichner, T. and R. Pethig (2009a): $\mathrm{CO}_{2}$ emmissions control with national emissions taxes and an international emissions trading scheme. European Economic Review 53, 625 -635 . 
Eichner, T. and R. Pethig (2009b): Efficient management of insecure fossil fuel imports through (!) taxing domestic green energy?, discussion paper, University of Siegen.

Fischer, C. and R.G. Newell (2008): Environmental and technology policies for climate change mitigation. Journal of Environmental Economics and Management 55, 142 $-162$.

Goulder, L.H. and K. Mathai (2000): Optimal CO2 abatement in presence of induced technological change. Journal of Environmental Economics and Management 39, 1 38.

Lehmann, P. (2009): Climate policies with pollution externalities and learning spillovers. UFZ discussion paper, Leipzig.

Menanteau, P. Finon, D. and M.L. Lamy (2003): Prices versus quantities: choosing policies for promoting the development of renewable energy. Energy Policy 31, 799 812.

Rauscher, M. (1994): On ecological dumping. Oxford Economic Papers 46, 822 - 840.

Santore, R., Robinson, H.D. and Y. Klein (2001): Strategic state-level environmental policy with asymmetric pollution spillovers. Journal of Public Economics 80, 199 224.

Trotignon, R. and A. Delbosc (2008): Allowance trading patterns during the EU ETS trial period: What does CITL reveal? Climate report issue No. 13, Paris.

Ulph, A. (1996): Environmental policy and international trade when governments and producers act strategically. Journal of Environmental Economics and Management 30, $265-281$. 